\title{
EFFICIENCY ESTIMATION OF NANOTECHNOLOGIES APPLIED IN CONSTRUCTED WELLS TO ACCELERATE FIELD DEVELOPMENT
}

\section{Extended Abstract:}

The modern stage of development of the oil industry in Russia is characterized by the necessity to develop intensively small and medium-sized oil fields containing the reserves related to the category of hardrecoverable but associated with the regions with developed industrial infrastructure. Limited input of them in development in previous years was due to the lack of innovative technologies that could significantly reduce the cost of extracted products and to reach the level of economic profitability.

The creation and use of new technologies, including nanosystems, reasonable application of them, the government's different types of preferences when developing such facilities allow us to consider them as substantial reserve of oil production.

One of the most important things that improve technical and economic performance of the development of low-producing deposits with hardrecoverable reserves is the intensification of reserves recovery, from the very beginning of the operation of the facilities.

The availability of wide range of technologies for primary and secondary formation exposing in well construction completion process, methods of influence on the bottom-hole zone, the use of various well designs require proper comparative evaluation of the effectiveness of these activities in different geologic conditions to justify their effective use and reduce risks of ineffective decision making.

For field situation in Western Siberia a study of dynamics of bottom-hole area purification degree change and productivity factor was conducted according to the data obtained from operation of producing wells. 
The paper describes the dependencies and models underlying the various algorithms to evaluate the effectiveness of formation exposing and impact on well bottom-hole zone with the purpose to intensify the process of oil extraction, to reduce the cost of extracted products and profitability increase when setting fields with hard to recover reserves into operation and further development of them.

The obtained results, methods and algorithms make it possible to increase efficiency of evaluation of nanotechnologies application outcome including application of nanosystems in well construction completion process. This is the basis for searching and proving technological solutions aimed at extension of resource base deposits that are within the borders of economic feasibility.

Key words: nanotechnology, well construction, productivity factor, bottomhole formation zone, hard-to-recover reserves, intensification.

DOI: dx.doi.org/10.15828/2075-8545-2018-10-1-113-131

MACHINE-READABLE INFORMATION ON CC-LICENSES (HTML-CODE) IN METADATA OF THE PAPER

$<$ a rel="license" href="http://creativecommons.org/licenses/by/4.0/" $><$ img alt="Creative Commons License" style="borderwidth:0" src="https://i.creativecommons.org/l/by/4.0/88x31.png" / $></ \mathrm{a}><$ br $/><$ span xmlns:dct="http://purl. org/dc/terms/" href="http://purl.org/dc/dcmitype/Text" property="dct:title" rel="dct:type" $>$ Efficiency estimation of nanotechnologies applied in constructed wells to accelerate field development $</$ span $>$ by $<$ a xmlns:cc="http:// creativecommons.org/ns\#" href="Nanotehnologii v stroitel'stve = Nanotechnologies in Construction. 2018, Vol. 10, no. 1, pp. 113-131. DOI: dx.doi. org/10.15828/2075-8545-2018-10-1-113-131" property="cc:attributionName" rel="cc:attributionURL" $>$ Mukhametshin V.V. $</ a>$ is licensed under a $<$ a rel="license" href="http://creativecommons.org/licenses/by/4.0/" $>$ Creative Commons Attribution 4.0 International License $</ \mathrm{a}>$. $<$ br $/>$ Based on a work at $<$ a xmlns:dct="http://purl.org $/ \mathrm{dc} /$ terms $/ "$ href=" http://nanobuild.ru/en_EN/nanobuild-1-2018/" rel="dct:source" > http://nanobuild.ru/en_EN/nanobuild-1-2018/</ $\mathrm{a}>$. $<\mathrm{br} />$ Permissions beyond the scope of this license may be available at $<$ a xmlns:cc="http:// creativecommons.org $/ \mathrm{ns} \# "$ href="vsh@of.ugntu.ru" rel="cc:morePermissions">vsh@of.ugntu.ru</a>.

\section{References:}

1. Shpurov I.V., Zakharenko V.A., Fursov A.Ya. Differentsyrovannyy analiz stepeni vovlecheniya i vyrabotannosti zapasov yurskikh zalezhey v predelakh Zapadno-Sibirskoy NGP [A differentiated analysis of the degree of involvement and the depletion of stocks of Jurassic deposits in the Western Siberian oil-and-gas province]. Nedropolzovanie XXI vek, 2015. № 1 (51). P. 12-19. (In Russian).

2. Dmitrievsky A.N., Eremin N.A. Innovacionnyy potentsial umnykh neftegazovykh tehnologiy [The innovative potential of the smart oil and gas technologies]. Geology, Geophysics and Development of Oil and Gas Fields, 2016. № 1. P. 4-9. (In Russian). 
3. Economides J.M., Nolte K.I. Reservoir stimulation. West Sussex, England: John Wiley and Sons, 2000. $856 \mathrm{p}$.

4. Muslimov R.Kh. Sovremennye metody povysheniya nefteizvlecheniya: proektirovanie, optimizatsiya i otsenka effektivnosti [Modern methods of oil recovery increasing: design, optimization and performance evaluation]. Kazan', FEN, 2005. 688 p. (In Russian).

5. Mukhametshin V.Sh. Zavisimost' nefteizvlecheniya ot plotnosti setki skvazhin pri razrabotke nizkoproduktivnyh karbonatnyh zalezhej [Dependence of crude-oil recovery on the well spacing density during development of low-producing carbonate deposits]. Neftyanoe khozyaystvo = Oil industry, 1989. № 12. P. 26-29. (In Russian).

6. Webb K.J., Black C.J.J., Tjetland G. A Laboratory Study Investigating Methods for Improving Oil Recovery in Carbonates. International Petroleum Technology Conference. Doha, Qatar, 2005. P. 1-6. DOI: doi.org/10.2523/IPTC-10506-MS.

7. Nasr-El-Din H.A., Van Domelen M.S., Sierra L., Welton T.D. Optimization of Surfactant-based Fluids for Acid Diversion. European Formation Damage Conference. Scheveningen, The Netherlands, 2007. P. 1-11. DOI: doi.org/10.2118/107687-MS.

8. Gomari K.A.R., Karoussi O., Hamouda A.A. Mechanistic Study of Interaction between Water and Carbonate Rocks for Enhancing Oil Recovery. Europec/EAGE Annual Conference and Exhibition. Vienna, Austria, 2006. P. 1-8. DOI: doi. org/10.2118/99628-MS.

9. Zeigman Yu.V., Lysenkov A.V., Mukhametshin V.V., Sultanov Sh.Kh., Kotenev Yu.A. $\mathrm{K}$ voprosu vybora tekhnologii kislotnogo vozdejstviya dlya intensifikacii dobychi nefti [Some aspects of an acidizing technology choice to enhance oil production]. Geology, Geophysics and Development of Oil and Gas Fields, 2017. № 6. P. 44-50. (In Russian).

10. Mukhametshin V.V. Ustranenie neopredelennostey pri reshenii zadach vozdeystviya na prizaboynuyu zonu skvazhin [Eliminating uncertainties in solving bottom hole zone stimulation tasks]. Bulletin of the Tomsk Polytechnic University. Geo Assets Engineering, 2017. Vol. 328, № 7. P. 40-50. (In Russian).

11. Khayredinov N.Sh., Popov A.M., Mukhametshin V.Sh. Povyshenie effektivnosti zavodneniya nizkoproduktivnyh zalezhej nefti v karbonatnyh kollektorah [Increasing the flooding efficiency of poor-producing oil deposits in carbonate]. Neftyanoe khozyaystvo = Oil industry, 1992. № 9. P. 18-20. (In Russian).

12. Gayvoronsky I.N., Merkulov A.A., Shumilov A.V., Savich A.D., Chernykh I.A., Shurov V.M. O vybore strategii zakanchivaniya neftegazovykh skvazhin [Choosing of oil and gas wells completion strategy]. Neftyanoe khozyaystvo = Oil industry, 2015. № 11. P. 104-108. (In Russian). 
13. Yakupov R.F., Mukhametshin V.Sh. Voprosy effektivnosti razrabotki nizkoproduktivnykh karbonatnykh kollektorov na primere Turneyskogo yarusa Tuymazinskogo mestorozhdeniya [Problem of efficiency of low-productivity carbonate reservoir development on example of Turnaisian stage of Tuymazinskoye field]. Neftyanoe khozyaystvo = Oil industry, 2013. № 12. P. 106-110. (In Russian).

14. Zeigman Yu.V., Mukhametshin V.Sh., Khafizov A.R., Kharina S.B. Prospects of Application of Multi-Functional Well Killing Fluids in Carbonate Reservoirs. SOCAR Proceedings, 2016. № 3. P. 33-39. DOI: dx.doi.org/10.5510/OGP20160300286. (In Russian).

15. Behrmann L., Huber K., McDonald B., Couët B., Dees J., Folse R., Handren P., Schmidt J., Snider P. Quo Vadis, Extreme Overbalance? Oilfield Review, 1996. P. 18-33.

16. Lestz R., Clarke J.N., Plattner D., Byrd A.C. Perforating for Stimulation: An Engineered Solution. SPE Drilling \& Completion, 2002. № 17 (1). P. 36-43.

17. Mukhametshin V.Sh. Gruppirovanie neftyanyh zalezhej i ego ispol'zovanie dlya povysheniya effektivnosti razrabotki mestorozhdenij [Oil pool grouping and its use in increasing field development efficiency]. Oil and Gas Geology, 1989. № 11. P. 22-26.

18. Mukhametshin V.V., Andreev V.E., Dubinsky G.S., Sultanov Sh.Kh., Akhmetov R.T. The Usage of Principles of System Geological-Technological Forecasting in the Justification of the Recovery Methods. SOCAR Proceedings, 2016. № 3. P. 46-51. DOI: dx.doi. org/10.5510/OGP20160300288. (In Russian).

19. Lungwitz B.R., Fredd C.N., Brady M.E., Miller M.J., Ali S.A., Hughes K.N. Diversion and Cleanup Studies of Viscoelastic Surfactant-Based Self-Diverting Acid. International Symposium and Exhibition on Formation Damage Control. Lafayette, Louisiana, 2004. P. 1-10. DOI: https://doi.org/10.2118/86504-MS.

20. Mukhametshin V.V. O neobhodimosti i sozdanii edinogo kompleksnogo metoda geologo-promyslovogo analiza i obobshcheniya effektivnosti vozdeystviya na prizaboynuyu zonu plasta [The need for creation of a unified comprehensive method of geological and field analysis and integration of data on effective influence on the bottom-hole formation zone]. Neftyanoe khozyaystvo = Oil industry, 2017. № 4. P. 80-84. (In Russian).

21. Mukhametshin V.Sh., Zeigman Yu.V., Andreev A.V. Ekspress-ocenka potenciala dobyvnyh vozmozhnostej zalezhej dlya opredeleniya effektivnosti primeneniya nanotekhnologij i neobhodimosti stimulirovaniya vvoda ih v razrabotku [Rapid assessment of deposit production capacity for determination of nanotechnologies application efficiency and necessity to stimulate their development]. Nanotehnologii v stroitel'stve $=$ Nanotechnologies in Construction, 2017. Vol. 9. № 3. P. 20-34. DOI: dx.doi.org/10.15828/2075-8545-2017-9-3-20-34. (In Russian). 
22. Zeigman Yu.V., Mukhametshin V.Sh., Sergeev V.V., Kinzyabaev F.S. Eksperimental'noe issledovanie vyazkostnyh svojstv emul'sionnyh sistem s soderzhaniem nanochastic $\mathrm{SiO}_{2}$ [Experimental study of viscosity properties of emulsion system with $\mathrm{SiO}_{2}$ nanoparticles]. Nanotehnologii v stroitel'stve $=$ Nanotehnologies in Construction, 2017. Vol. 9, № 2. P. 16-38. - DOI: dx.doi.org / 10.15828/2075-8545-2017-9-2-1638. (In Russian).

23. Cherevko M.A., Yanin K.E. Pervye rezultaty primeneniya mnogostadiynykh gidrorazryvov plastov v gorizontalnykh skvazhinakh Priobskogo mestorozhdeniya [The first results of the application of multi-stage hydraulic fracturing in horizontal wells of Priobskoye field]. Neftyanoe khozyaystvo = Oil industry, 2015. № 2. P. 74-77. (In Russian).

24. Kadyrov R.R., Nizaev R.Kh., Yartiev A.F., Mukhametshin V.V. Ogranichenie vodopritoka $\mathrm{v}$ gorizontalnykh skvazhinakh na mestorozhdeniyakh s trudnoizvlekaemymi zapasami nefti [A novel water shut-off technique for horizontal wells at fields with hardto-recover oil reserves]. Neftyanoe khozyaystvo = Oil industry, 2017. № 5. P. 44-47. (In Russian).

25. Mukhametshin V.V. Adaptatsiya solyano-kislotnogo vozdeystviya na zalezhakh v karbonatnykh kollektorakh [Adaptation of sulphuric acid treatment on carbonate reservoir layers]. Neftegazovoe delo, 2006. Vol. 4, № 1. P. 127-131.

26. Mukhametshin V.V., Andreev V.E., Zeigman Yu.V., Kotenev Yu.A., Sultanov Sh.Kh. Snizhenie riskov prinyatiya nizkoeffektivnykh upravlyayushchikh resheniy pri ispolzovanii kislotnykh sostavov, predotvrashchayushchikh emulsioobrazovanie [Reducing risks of low-efficiency managerial decision-making when using acidization compositions preventing emulsification]. Geology, Geophysics and Development of Oil and Gas Fields, 2017. № 5. P. 36-42. (In Russian).

27. Mukhametshin V.Sh., Popov A.M., Goncharov A.M. Promyslovoe obosnovanie vybora skvazhin i parametrov vozdejstviya pri provedenii solyanokislotnyh obrabotok [The commercial rationale for the wells and impact parameters selection while hydrochloric acid treatments carrying out]. Neftyanoe khozyaystvo = Oil Industry, 1991. № 6. P. 32-33.

28. Kanalin V.G. Interpretaciya geologo-promyslovoy informacii pri razrabotke neftyanykh mestorozhdeniy [Geological information interpretation in the oil fields development]. Moscow, Nedra, 1984. 184 p.

29. Dobrynin V.M. Deformaciya i izmenenie fizicheskikh svoystv kollektorov nefti i gaza [Oil and gas reservoirs deformation and physical properties change]. Moscow: Nedra, 1970. $239 \mathrm{p}$.

30. Musin K.M., Khusainov V.M., Gallyamov R.R., Musabirova N.Kh, Gibadullin A.A., Shipilova K.F. Obosnovanie predelno-dopustimykh i optimalnykh zaboynykh davleniy 
dlya karbonatnykh plastov (na primere turneyskogo yarusa Krasnogorskogo mestorozhdeniya) [Maximum permissible and optimal bottom-hole pressures substantiation for carbonate reservoirs (on the example of the Krasnogorsk oil field Tournaisian tier)]. Proceedings of TatNIPIneft. Moscow, ZAO «Izdatel'stvo «Neftyanoe khozyaystvo", 2015. Issue 83. P. 106-113.

31. Akhmetov R.T., Mukhametshin V.V., Andreev A.V. Interpretatsiya krivykh kapillyarnogo davleniya pri smeshannoy smachivaemosti [Interpretation of capillary pressure curves in case of mixed-wettability]. Geology, Geophysics and Development of Oil and Gas Fields, 2017. № 4. P. 40-43.

32. Kanalin V.G., Kapralova M.K. Issledovanie izmeneniya koeffitsienta produktivnosti pri razrabotke zalezhey nefti Zapadnoy Sibiri [The productivity factor changes study in the Western Siberia oil deposits development]. Neftepromyslovoe delo, 1981. № 11. P. 10-12.

33. Andreev A.V., Mukhametshin V.Sh., Kotenev Yu.A. Deposit Productivity Forecast in Carbonate Reservoirs with Hard to Recover Reserves. SOCAR Proceedings, 2016. № 3. P. 40-45. DOI: dx.doi.org/10.5510/OGP20160300287. (In Russian).

34. Akhmetov R.T., Andreev A.V., Mukhametshin V.V. Metodika prognoza ostatochnoj neftenasyshchennosti i koefficienta vytesneniya po dannym geofizicheskih issledovanij dlya ocenki effektivnosti primeneniya nanotekhnologij [Residual oil saturation and the displacement factor prediction methodology based on geophysical studies data to evaluate efficiency of nanotechnologies application]. Nanotehnologii v stroitel'stve = Nanotechnologies in Construction, 2017. Vol. 9, № 5. P. 116-133. DOI: dx.doi. org/10.15828/2075-8545-2017-9-5-116-133. (In Russian).

35. Akhmetov R.T., Zeigman Yu.V., Mukhametshin V.V., Andreev A.V., Sultanov Sh.Kh. Prognoz pokazatelya smachivaemosti produktivnyh plastov po ob"emnomu soderzhaniyu ostatochnoj vody [Forecast of wettability index in productive formations by volume of residual water content]. Higher Educational Institutions News. Oil and Gas, 2017. № 2. P. 39-43.

\section{DEAR COLLEAGUES!}

THE REFERENCE TO THIS PAPER HAS THE FOLLOWING CITATION FORMAT:

Mukhametshin V.V. Efficiency estimation of nanotechnologies applied in constructed wells to accelerate field development. Nanotehnologii v stroitel'stve = Nanotechnologies in Construction. 2018, Vol. 10, no. 1, pp. 113-131. DOI: dx.doi. org/10.15828/2075-8545-2018-10-1-113-131. (In Russian). 
Автор: МУХАМЕТШИН Вячеслав Вячеславович, канд. техн. наук, доцент каф. «Разработка и эксплуатация нефтяных и газонефтяных месторождений», Федеральное государственное бюджетное образовательное учреждение высшего образования «Уфимский государственный нефтяной технический университет»; ул. Космонавтов, 1, г. Уфа, Республика Башкортостан, Россия, 450062, vsh@of.ugntu.ru

\section{ОЦЕНКА ЭФФЕКТИВНОСТИ ИСПОЛЬЗОВАНИЯ НАНОТЕХНОЛОГИЙ ПОСЛЕ ЗАВЕРШЕНИЯ СТРОИТЕЛЬСТВА СКВАЖИН, НАПРАВЛЕННЫХ НА УСКОРЕНИЕ ВВОДА МЕСТОРОЖДЕНИЙ НЕФТИ В РАЗРАБОТКУ}

АННОТАЦИЯ К СТАТЬЕ (АВТОРСКОЕ РЕЗЮМЕ, РЕФЕРАТ):

Современный этап развития нефтяной отрасли России характеризуется необходимостью ввода в активную разработку мелких и средних месторождений нефти, содержащих запасы, отнесенные к категории трудноизвлекаемых, но приуроченных к регионам с развитой производственной инфраструктурой. Ограниченный ввод их в разработку в предыдущие годы объяснялся отсутствием инновационных технологий, позволяющих существенно снизить себестоимость добываемой продукции.

Создание и использование новых технологий, в том числе с использованием наносистем, обоснованное их применение, введение государством различного рода преференций при разработке таких объектов позволяют рассматривать их существенным резервом добычи нефти.

Одним из важнейших моментов, позволяющих повысить технико-экономические показатели разработки низкопродуктивных залежей с трудноизвлекаемыми запасами, является интенсификация выработки запасов, причем с самого начала эксплуатации объектов.

Наличие широкого круга технологий первичного и вторичного вскрытия пластов в процессе завершения строительства скважин, методов воздействия на призабойную зону и пласт, использование различных конструкций скважин требуют корректной сравнительной оценки результативности этих мероприятий в различных геолого-промысловых условиях для обоснования областей их эффективного использования и снижения рисков принятия неэффективных решений. 
Для условий месторождений Западной Сибири проведено изучение динамики изменения степени очистки призабойной зоны и коэффициента продуктивности скважин по фактическим данным эксплуатации добывающих скважин.

Получены зависимости и модели, лежащие в основе различных алгоритмов, позволяющих оценивать эффективность вскрытия пластов и воздействие на призабойную зону скважин с целью интенсификации процесса нефтеизвлечения, снижения себестоимости добываемой продукции и увеличения рентабельности при вводе в эксплуатацию и дальнейшей разработки месторождений с трудноизвлекаемыми запасами.

Полученные результаты методики и алгоритмы позволяют повышать эффективность оценки результативности использования инновационных технологий, в том числе с использованием наносистем в процессе завершения строительства скважин, и на этой основе проводить поиск и обоснование технологических решений, направленных на расширение использования ресурсной базы месторождений, находящихся у границы экономической рентабельности.

Ключевые слова: нанотехнологии, строительство скважин, коэффициент продуктивности, призабойная зона пласта, трудноизвлекаемые запасы, интенсификация.

DOI: dx.doi.org/10.15828/2075-8545-2018-10-1-113-131

МАШИНОЧИТАЕМАЯ ИНФОРМАЦИЯ О СС-ЛИЦЕНЗИИ в МЕТАДАННЫХ СТАТЬИ (НTML-КОД):

< a rel="license" href="http://creativecommons.org/licenses/by/4.0/"><img alt="Лицензия Creative Commons" style="borderwidth:0" src="https://i.creativecommons.org/l/by/4.0/88x31.png" / ></a ><br / Произведение «<span xmlns:dct="http:// purl.org/dc/terms/" href="http://purl.org/dc/dcmitype/Text" property="dct:title" rel="dct:type">Оценка эффективности использования нанотехнологий после за- вершения строительства скважин, направленных на ускорение ввода месторождений нефти в разработку </span >» созданное автором по имени <a xmlns:cc="http://creativecommons.org/ns\#" href="Нанотехнологии в строительстве. - 2018. - Том 10, № 1. - C. 113-131. - DOI: dx.doi.org/10.15828/2075-8545-2018-101-113-131" property="cc:attributionName" rel="cc:attributionURL"> Мухаметшин В.В. </а >, публикуется на условиях <а rel="license" href="http://creativecommons.org/licenses/by/4.0/">лицензии Сreative Сommons С указанием авторства 4.0 Всемирная </a $>$. $<$ br /> Основано на произведении c < a xmlns:dct="http://purl.org/dc/terms/" href="http://nanobuild.ru/ru_ RU/nanobuild-1-2018/" rel="dct:source">http://nanobuild.ru/ru_RU/nanobuild-1-2018/</a >.<br />Paзрешения, выходящие за рамки данной лицензии, могут быть доступны на странице <a xmlns:cc="http://creativecommons.org/ns\#" href="vsh@ of.ugntu.ru" rel="cc:morePermissions"> vsh@of.ugntu.ru $</ \mathrm{a}>$. 
овременный этап развития нефтяной отрасли России характеризуется необходимостью ввода в активную разработку мелких и средних месторождений нефти, содержащих запасы, отнесенные к категории трудноизвлекаемых, но приуроченных к регионам с развитой производственной инфраструктурой. Ограниченный ввод их в разработку в предыдущие годы объяснялся отсутствием инновационных технологий, позволяющих существенно снизить себестоимость добываемой продукции [1-5].

Создание и использование новых технологий, в том числе с использованием наносистем, обоснованное их применение, введение государством различного рода преференций при разработке таких объектов позволяют рассматривать их существенным резервом добычи нефти.

Одним из важнейших моментов, позволяющих повысить техникоэкономические показатели разработки низкопродуктивных залежей с трудноизвлекаемыми запасами, является интенсификация выработки запасов, причем с самого начала эксплуатации объектов [6-11].

Наличие широкого круга технологий первичного и вторичного вскрытия пластов в процессе завершения строительства скважин [1217], методов воздействия на призабойную зону и пласт [18-22], использование различных конструкций скважин [23-24] требуют корректной сравнительной оценки результативности этих мероприятий в различных геолого-промысловых условиях для обоснования областей их применения и снижения рисков принятия неэффективных решений [25-27].

В промысловой практике одним из основных параметров, используемых для оценки эффективности различных мероприятий, является коэффициент продуктивности $\left(K_{\text {прод }}\right.$, т/(сут • МПа)) скважин, который интегрально учитывает фильтрационно-емкостные свойства пласта в точке вскрытия его скважиной [28]. Однако его использование должно быть «очищено» от посторонних «шумов», поскольку этот важный параметр оценки подвержен изменению не только в результате воздействия на призабойную зону пласта (ПЗП), но и в результате очистки 
призабойной зоны от продуктов бурения, начала фильтрации многофазной жидкости, снижения пластового давления ниже давления насыщения, упругих деформаций пласта [29-31]. Кроме того, использование коэффициента продуктивности как параметра оценки эффективности применения различных технологий первичного и вторичного вскрытия пластов и воздействия на призабойную зону при освоении скважин невозможно из-за отсутствия измерений $K_{\text {прод }}$ до проведения мероприятий.

Для снятия вышеприведенных неопределенностей, устранения «посторонних шумов» и получения возможности объективной оценки эффективности проведения мероприятий, направленных на интенсификацию добычи нефти до пуска скважин в эксплуатацию, было выбрано более 300 скважин месторождений Западной Сибири, приуроченных в тектоническом отношении $\kappa$ Ярсомовскому прогибу и Сургутскому своду, в стратиграфическом - к пластам БС ${ }_{10}, \mathrm{БC}_{11}$ и ЮС.

Обязательными условиями выбора скважин были:

- вскрытие пласта на глинистом растворе и перфорация колонны из расчета 20 отв/пог.м;

- при освоении и в период очистки призабойной зоны отсутствие проведения каких-либо мероприятий по воздействию на ПЗП.

По этим скважинам были выбраны значения коэффициентов продуктивности, определенные:

- п при обводненности продукции менее $15 \%$;

- в начальный период разработки при отсутствии закачки в пласт воды;

- в период стабилизации после завершения очистки призабойной зоны от продуктов бурения (после выхода скважины на максимальный оптимальный дебит (МОД) и до момента начала изменения $K_{\text {прод }}$ в силу различных причин).

Считалось, что скважина достигла МОД (завершение процесса очистки призабойной зоны) в момент, после которого он не изменялся более, чем на $10 \%$, т.е. на величину погрешности определения дебита скважин.

Анализ изменения $K_{\text {прод }}$ и МОД во времени показал, что время очистки призабойной зоны от продуктов бурения изменяется от 1 до 12 месяцев, составляя в среднем 4,5 мес. Период стабилизации коэффициента продуктивности составляет в среднем около 2,5 лет. Выводы, близкие к полученным по иным месторождениям Западной Сибири, представ- 
лены в работе [32], в которой проведено изучение изменения коэффициента продуктивности скважин во времени. Выделено четыре периода: первый - несколько месяцев происходит очистка ПЗП от фильтрата бурового раствора, и коэффициент продуктивности увеличивается; второй - стабилизация $K_{\text {прод }}$ в течение $3-5$ лет, а затем снижение вследствие уменьшения пластового давления, деформации пород-коллекторов, начала фильтрации многофазной жидкости, уменьшения работающей толщины из-за обводнения продукции и снижения депрессии на пласт; третий - рост и стабилизация в течение 2-6 лет за счет увеличения работающей толщины из-за увеличения депрессии (организация заводнения) и обратной упругой деформации; четвертый - резкое снижение коэффициента продуктивности (8-12 годы разработки) ввиду выключения из работы низкопроницаемых пропластков, особенно на участках с повышенной геологической неоднородностью. Делается заключение, что продуктивность отражает реальные свойства пласта во втором периоде в течение 2-5 лет после начала эксплуатации скважин [32].

Однако разброс значений этого параметра довольно значителен, что является отражением геологических особенностей пластов и требует дифференцированного подхода при решении задач подобного рода. В связи с этим был проведен кластерный анализ и выделено четыре группы скважин:

- $\quad$ 1, 2 - пласты БС 10 и БС 11 , соответственно, Ярсомовского прогиба;

- $\quad 3,4$ - пласты БС 10 и ЮС, соответственно, Сургутского свода.

Изучение изменения коэффициента продуктивности скважин во времени с момента освоения и до выхода на максимальный оптимальный дебит показало, что кривые, характеризующие динамику изменения коэффициента продуктивности по выделенным группам скважин, достаточно близко располагаются друг от друга в координатах $K_{\text {прод }}^{\prime \prime}$ $K_{\text {прод }}-t^{\prime} / t_{0}$, где $K_{\text {прод }}^{\prime \prime}$ текущее значение коэффициента продуктивности в момент времени $t^{\prime}$, т.е. времени, прошедшего с момента пуска скважины в эксплуатацию; $\kappa_{\text {прод }}$ - коэффициент продуктивности, определенный в момент времени $t_{0}$, т.е. времени, прошедшего с момента пуска скважины в эксплуатацию до момента выхода ее на максимальный оптимальный дебит. На рис. представлены осредненные кривые, характеризующие изменения коэффициента продуктивности во времени. Точками обозначены средние значения отношения $K_{\text {прод }}^{\prime} / K_{\text {прод }}$ в интервалах параметра $t^{\prime} / t_{0}$ от 0 до 0,1 ; от 0,1 до 0,2 ; от 0,9 до 1,0 и при значе- 
нии $t^{\prime} / t_{0}=1,0$. Вид зависимостей на рис. определялся путем перебора аппроксимирующих функций различного вида, исходя из значений коэффициентов корреляции и относительных погрешностей.

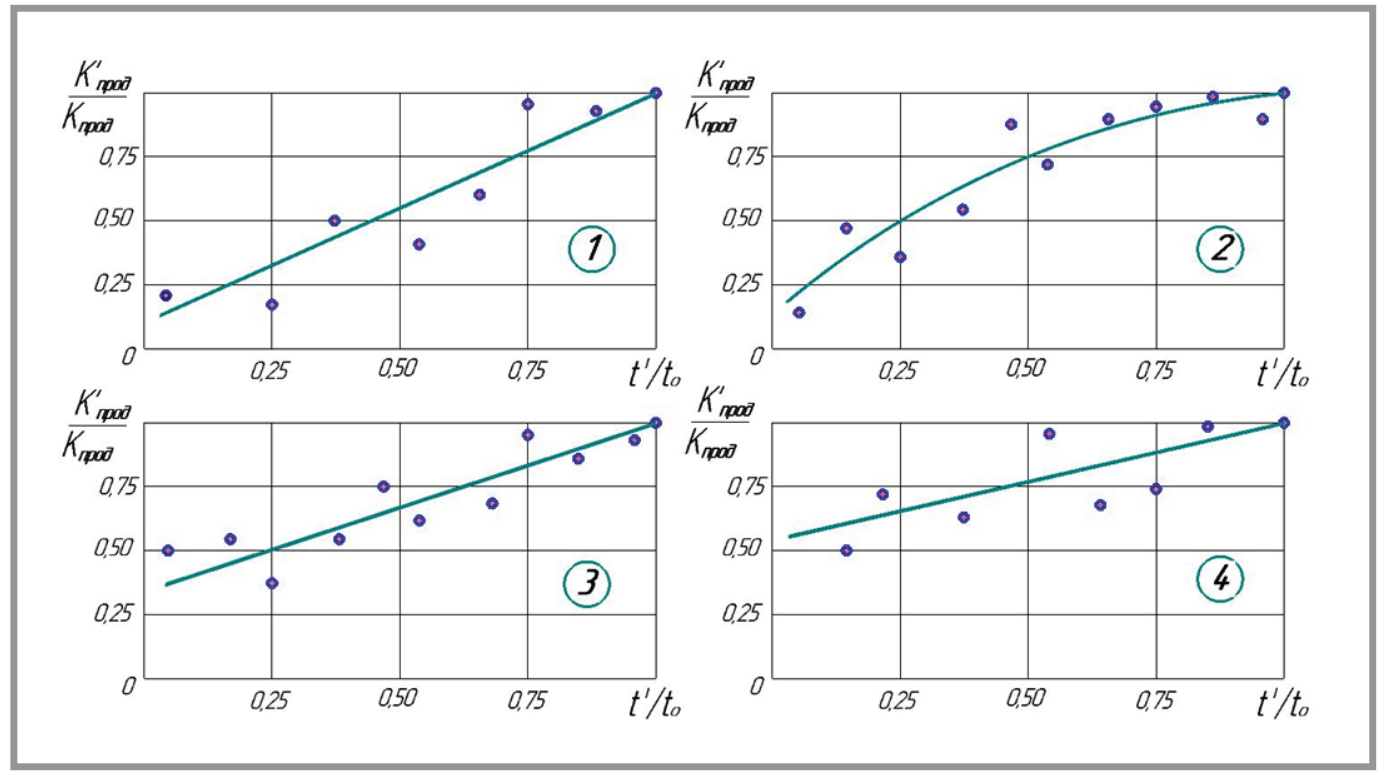

Рис. Изменение коэффициента продуктивности скважин в период очистки призабойной зоны пласта: $1,2,3,4$ - группы скважин

Зависимости, представленные на рис., наилучшим образом описываются функциями следующего вида (1):

$$
\begin{aligned}
& \left.K_{\text {прод }}^{\prime} / K_{\text {прод }}=0,1+0,9 t^{\prime} / t_{0} \text { (по скважинам группы } 1\right) ; \\
& K_{\text {прод }}^{\prime} / K_{\text {прод }}=\frac{t^{\prime} / t_{0}}{0,28+0,72 t^{\prime} / t_{0}}(\text { по скважинам группы } 2) ; \\
& K_{\text {прод }}^{\prime} / K_{\text {прод }}=0,36+0,64 t^{\prime} / t_{0}(\text { по скважинам группы } 3) ; \\
& \left.K_{\text {прод }}^{\prime} / K_{\text {прод }}=0,53+0,47 t^{\prime} / t_{0} \text { (по скважинам группы } 4\right) .
\end{aligned}
$$


Видно, что в интервале изменения параметра $t^{\prime} / t_{0}$ от 0,05 до 1,0 , т.е. практически с момента пуска скважины в эксплуатацию и до момента выхода на максимальный оптимальный дебит, происходит закономерное увеличение коэффициента продуктивности за счет очистки призабойной зоны пласта. Причем максимальное значение продуктивности имеет место в момент выхода скважины на максимальный оптимальный дебит. Характер очистки призабойной зоны при этом в условиях различных групп скважин имеет как определенные сходства, так и различия.

Необходимо отметить, что наиболее продуктивные скважины второй группы характеризуются высокой степенью загрязненности призабойной зоны после выхода из бурения ввиду проникновения большого объема фильтрата бурового раствора по высокопроницаемым пропласткам. При этом после пуска скважин в эксплуатацию происходит более интенсивное, относительно других групп, восстановление продуктивности в первую половину восстановительного периода, затем это восстановление замедляется. Скважины первой группы имеют меньшую продуктивность, и процесс очистки идет равномерно на протяжении всего периода восстановления. Скважины третьей группы имеют продуктивность в 3-5 раз меньшую, чем скважины групп 1, 2. Видно, что фильтрат бурового раствора в меньшей мере проникает в пласт и ухудшает реальные свойства пласта, однако процесс полного восстановления идет аналогично скважин второй группы. Самой низкой продуктивностью обладают скважины четвертой группы, и особенностью этой группы является менее существенная степень снижения реальных добывных возможностей после ввода в эксплуатацию (около 0,5$)$, однако тот фильтрат, который внедрился в низкопроницаемые разности пород, вымывается довольно медленно ввиду усиленного проявления поверхностно-молекулярных явлений.

На втором этапе было изучено влияние параметров, характеризующих условия залегания, геолого-физические и физико-химические свойства пластов и насыщающих их флюидов, определение которых производится достаточно точно на стадии проведения геолого-разведочных работ и в процессе проведения каротажа скважин [33-35], на изменение значений коэффициентов продуктивности, определенных после очистки призабойной зоны в период их стабилизации.

При построении многомерных моделей была использована регрессия по главным компонентам, которая позволила устранить коррели- 
рованность аргументов, обойтись меньшим их числом без существенной потери информации и получить более устойчивые модели.

Полученные уравнения регрессии, выраженные через исходные параметры, имеют следующий вид:

$$
\begin{aligned}
& K_{\text {прод }}=-5,78+0,04 H_{\text {зал }}+2,08 H_{\text {перф }}+0,69 H_{\text {проп }}-8,66 K_{\Pi}-2,16 K_{\mathrm{p}}+ \\
& +17,32 \alpha_{\text {сп }}+0,95 \rho_{\text {ик }}-0,14 \rho_{2,25}-0,83 \mathrm{M}(\text { БК })+8,28 \mu_{\mathbf{H}}+127,04 \rho_{\mathbf{H}}-0,63 G- \\
& -8,28 P_{\text {нас }}
\end{aligned}
$$

(по скважинам группы 1);

$$
\begin{aligned}
& K_{\text {прод }}=247,32-0,07 H_{\text {зал }}+5,78 H_{\text {перф }}-7,02 H_{\text {проп }}-12,52 K_{\text {п }}+0,23 K_{\mathrm{p}}+ \\
& +6,49 \alpha_{\text {сп }}-1,86 \rho_{\text {ик }}+1,12 \rho_{2,25}-2,02 \mathrm{M}(\text { БК })-12,52 \rho_{\mathrm{H}}+0,009 G
\end{aligned}
$$

(по скважинам группы 2);

$$
\begin{aligned}
& K_{\text {прод }}=-284,43+0,04 H_{\text {зал }}+0,02 H_{\text {перф }}+0,28 H_{\text {проп }}+368 K_{\Pi}+1,71 K_{\mathrm{p}}- \\
& -20 \alpha_{\text {сп }}+0,65 \rho_{\text {ик }}+0,26 \rho_{2,25}+0,48 \mathrm{M(БК)}
\end{aligned}
$$

(по скважинам группы 3);

$$
\begin{aligned}
& K_{\text {прод }}=50,2-0,002 H_{\text {зал }}+0,12 H_{\text {перф }}+0,14 H_{\text {проп }}+2 K_{\mathrm{p}}+2,94 \alpha_{\text {сп }}- \\
& -0,03 \rho_{\text {ик }}-0,03 \rho_{2,25}+0,009 \mathrm{M}(\text { БК })+0,04 G-1,81 P_{\text {пл }}-0,04 t_{\text {пл }}
\end{aligned}
$$

(по скважинам группы 4);

$$
\begin{aligned}
& K_{\text {прод }}=-34,6-0,02 H_{\text {зал }}+0,5 H_{\text {перф }}+0,76 H_{\text {проп }}-41,7 K_{\Pi}-1,42 K_{\mathrm{p}}+ \\
& +1,41 \alpha_{\text {сп }}+0,44 \rho_{\text {ик }}+0,20 \rho_{2,25}-0,31 \mathrm{M}(\text { БК })-4,7 \mu_{\mathrm{H}}-22,8 \rho_{\mathrm{H}}+0,12 G- \\
& -0,84 P_{\text {нас }}-0,03 P_{\text {пл }}+2,19 t_{\text {Пл }}
\end{aligned}
$$

(по скважинам групп 1-4),

где $H_{\text {зал }}$ - глубина залегания кровли пласта, м; $P_{\text {пл }}-$ начальное пластовое давление, МПа; $t_{\text {пл }}$ - начальная пластовая температура, ${ }^{\circ} \mathrm{C}$; $H_{\text {перф }}$ - перфорированная эффективная нефтенасыщенная толщина пласта, м; $H_{\text {проп }}$ - средняя толщина нефтенасыщенных пропластков, м; $K_{\mathrm{p}}-$ коэффициент расчлененности пласта; $K_{\text {п }}$ - коэффициент песчанистости; $\alpha_{\text {сп }}$ - относительная амплитуда ПС; $\rho_{\text {ик }}$ - сопротивление пласта по ИК, Омм; $\rho_{2,25}-$ сопротивление пласта по двухметровому зонду, Омм;

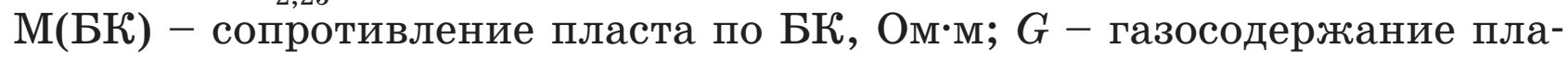
стовой нефти, $\mathrm{m}^{3} / \mathrm{T} ; P_{\text {нас }}$ - давление насыщения нефти газом, МПа; $\mu_{\text {н }}-$ вязкость пластовой нефти, мПа'с; $\rho_{\text {н }}-$ плотность пластовой нефти, т/ $\mathrm{M}^{3}$. 
Необходимо отметить, что, если коэффициенты множественной корреляции моделей (2) - (5) изменяются от 0,577 до 0,733 , то в целом по всем скважинам он равен 0,496 , что указывает на обоснованность проведенной кластеризации скважин и необходимость дифференцированного подхода в решении подобных задач.

Таким образом, использование полученных зависимостей позволяет:

- оценивать время очистки призабойной зоны пласта, проведя исследование методом установившихся отборов при пуске скважин в эксплуатацию или в период очистки по формулам:

$$
\mathrm{t}_{0}=0,9 \mathrm{t}^{\prime} \mathrm{K}_{\text {nрод }} /\left(\mathrm{K}_{\text {nрод }}^{\prime}-0,1 \mathrm{~K}_{\text {nрод }}\right)
$$

(по скважинам группы 1);

$$
t_{0}=\frac{t^{\prime}\left(1-0,72 K_{\text {прод }}^{\prime}\right) / K_{\text {прод }}}{0,28 K_{\text {прод }}^{\prime} / K_{\text {прод }}}
$$

(по скважинам группы 2);

$$
\mathrm{t}_{0}=0,64 \mathrm{t}^{\prime} \mathrm{K}_{\text {nрод }} /\left(\mathrm{K}_{\text {npod }}^{\prime}-0,36 \mathrm{~K}_{\text {nрод }}\right)
$$

(по скважинам группы 3 );

$$
\mathrm{t}_{0}=0,47 \mathrm{t}^{\prime} \mathrm{K}_{\text {прод }} /\left(\mathrm{K}_{\text {nрод }}^{\prime}-0,53 \mathrm{~K}_{\text {прод }}\right)
$$

(по скважинам группы 4),

при этом на использование зависимостей (7) - (10) накладываются ограничения: $K_{\text {прод }}^{\prime \prime} / K_{\text {прод }}>0,2 ; t_{0}<610$ суток;

- оценивать эффективность воздействия на ПЗП при пуске скважины в эксплуатацию по значениям $K_{\text {прод }}^{\prime \prime} K_{\text {прод }}$. Эффект при этом определяется с использованием зависимостей, представленных на рис., как разница между эталонным значением $K_{\text {прод }}^{\prime \prime} / K_{\text {прод }}$ при $t^{\prime}=0$ и $t^{\prime} / t_{0}=0$ и фактическим значением $K_{\text {прод }}^{\prime \prime} K_{\text {прод; }}$;

- прогнозировать начальный дебит скважин и дебит после очистки ПЗП (при условии вскрытия пласта на глинистом растворе и проведении кумулятивной перфорации из расчета 20 отв/пог.м);

- оценивать эффективность иных методов первичного и вторичного методов вскрытия пластов по значениям времени очистки ПЗП и значениям $K_{\text {прод }}$ после очистки призабойной зоны, а также по динамике изменения $K_{\text {прод }}^{\prime}$ в период очистки ПЗП; 
- определять эффективность методов воздействия на ПЗП по значениям времени очистки, значениям $K_{\text {прод }}$ на момент очистки, а также по динамике изменения $K_{\text {прод }}^{\prime \prime}$ в период очистки;

- оценивать эффективность бурения скважин различной конструкции.

Полученные результаты и алгоритмы позволяют повысить эффективность оценки результативности технологий, направленных на расширение ресурсной базы месторождений с трудноизвлекаемыми запасами.

\section{Библиографический список:}

1. Шпуров И.В. Дифференцированный анализ степени вовлечения и выработанности запасов юрских залежей в пределах Западно-Сибирской НГП / И.В. Шпуров, В.А. Захаренко, А.Я. Фурсов // Недропользование XXI век. 2015. - № 1(51). - С. 12-19.

2. Дмитриевский А.Н. Инновационный потенциал умных нефтегазовых технологий / А.Н. Дмитриевский, Н.А. Еремин // Геология, геофизика и разработка нефтяных и газовых месторождений. - 2016. - № 1. - С. 4-9.

3. Economides J.M. Reservoir stimulation / J.M. Economides, K.I. Nolte. - West Sussex, England: John Wiley and Sons, 2000. - 856 p.

4. Муслимов P.X. Современные методы повышения нефтеизвлечения: проектирование, оптимизация и оценка эффективности. - Казань: ФЭН, 2005. - 688 с.

5. Мухалетшин В.ШІ. Зависимость нефтеизвлечения от плотности сетки скважин при разработке низкопродуктивных карбонатных залежей // Нефтяное хозяйство. -1989 . - № 12. - С. 26-29.

6. Webb K.J. A Laboratory Study Investigating Methods for Improving Oil Recovery in Carbonates / K.J. Webb, C.J.J. Black, G. Tjetland // International Petroleum Technology Conference. Doha, Qatar, 2005. P. 1-6. DOI: doi.org/10.2523/IPTC10506-MS.

7. Optimization of Surfactant-based Fluids for Acid Diversion / H.A. NasrEl-Din, M.S. Van Domelen, L. Sierra, T.D. Welton // European Formation Damage Conference. Scheveningen, The Netherlands, 2007. P. 1-11. DOI: doi. org/10.2118/107687-MS.

8. Gomari K.A.R. Mechanistic Study of Interaction between Water and Carbonate Rocks for Enhancing Oil Recovery / K.A.R. Gomari, O. Karoussi, A.A. Hamouda // 
Europec/EAGE Annual Conference and Exhibition. Vienna, Austria, 2006. P. 1-8. DOI: doi.org/10.2118/99628-MS.

9. $\quad$ в вопросу выбора технологии кислотного воздействия для интенсификации добычи нефти / Ю.В. Зейгман, А.В. Лысенков, В.В. Мухаметшин, Ш.Х. Султанов, Ю.А. Котенёв // Геология, геофизика и разработка нефтяных и газовых месторождений. - 2017. - № 6. - С. 44-50.

10. Мухалетшин В.В. Устранение неопределенностей при решении задач воздействия на призабойную зону скважин // Известия Томского политехнического университета. Инжиниринг георесурсов. - 2017. - Т. 328, № 7. - С. 40-50.

11. Хайрединов Н.Ш. Повышение эффективности заводнения низкопродуктивных залежей нефти в карбонатных коллекторах / Н.Ш. Хайрединов, А.М. Попов, В.Ш. Мухаметшин // Нефтяное хозяйство. - 1992. - № 9. - С. 18-20.

12. О выборе стратегии закачивания нефтегазовых скважин / И.Н. Гайворонский, А.А. Меркулов, А.В. Шумилов, А.Д. Савич, И.А. Черных, В.М. Шуров // Нефтяное хозяйство. - 2015. - № 11. - С. 104-108.

13. Якупов Р.Ф. Вопросы эффективности разработки низкопродуктивных карбонатных коллекторов на примере турнейского яруса Туймазинского месторождения / Р.Ф. Якупов, В.Ш. Мухаметшин // Нефтяное хозяйство. - 2013. № 12. - C. 106-110.

14. Prospects of Application of Multi-Functional Well Killing Fluids in Carbonate Reservoirs / Yu.V. Zeigman, V.Sh. Mukhametshin, A.R. Khafizov, S.B. Kharina // SOCAR Proceedings, 2016. № 3. P. 33-39. DOI: dx.doi.org/10.5510/ OGP20160300286.

15. Quo Vadis, Extreme Overbalance? / L. Behrmann, K. Huber, B. McDonald, B. Couët, J. Dees, R. Folse, P. Handren, J. Schmidt, P. Snider // Oilfield Review, 1996. P. 18-33.

16. Perforating for Stimulation: An Engineered Solution / R. Lestz, J.N. Clarke, D. Plattner, A.C. Byrd // SPE Drilling \& Completion, 2002. № 17 (1). P. 36-44.

17. Мухалетшин В.Ш. Группирование нефтяных залежей и его использование для повышения эффективности разработки месторождений // Геология нефти и газа. -1989 . - № 11. - С. 22-26.

18. The Usage of Principles of System Geological-Technological Forecasting in the Justification of the Recovery Methods / V.V. Mukhametshin, V.E. Andreev, G.S. Dubinsky, Sh.Kh. Sultanov, R.T. Akhmetov // SOCAR Proceedings, 2016. № 3. P. 46-51. DOI: dx.doi.org/10.5510/OGP20160300288.

19. Diversion and Cleanup Studies of Viscoelastic Surfactant-Based Self-Diverting Acid / B.R. Lungwitz, C.N. Fredd, M.E. Brady, M.J. Miller, S.A. Ali, K.N. Hughes // 
International Symposium and Exhibition on Formation Damage Control. Lafayette, Louisiana, 2004. P. 1-10. DOI: https://doi.org/10.2118/86504-MS.

20. Мухалетшин В.В. О необходимости и создании единого комплексного метода геолого-промыслового анализа и обобщения эффективности воздействия на призабойную зону пласта // Нефтяное хозяйство. - 2017. - № 4. - С. 80-84.

21. Мухалетшин В.Ш., Зейглан Ю.В., Андреев А.В. Экспресс-оценка потенциала добывных возможностей залежей для определения эффективности применения нанотехнологий и необходимости стимулирования ввода их в разработку / Нанотехнологии в строительстве. - 2017. - Том 9, № 3. - C. 20-34. - DOI: dx.doi.org/10.15828/2075-8545-2017-9-3-20-34.

22. Зейглан Ю.В., Мухалетшин В.Ш., Сергеев В.В., Кинзябаев Ф.С. Экспериментальное исследование вязкостных свойств эмульсионных систем с содержанием наночастиц $\mathrm{SiO}_{2} / /$ Нанотехнологии в строительстве. - 2017. - Том 9, № 2. C. 16-38. - DOI: dx.doi.org/10.15828/2075-8545-2017-9-2-16-38.

23. Черевко M.A. Первые результаты применения многостадийных гидроразрывов пластов в горизонтальных скважинах Приобского месторождения / М.А. Черевко, К.Е. Янин // Нефтяное хозяйство. - 2015. - № 2. - С. 74-77.

24. Ограничение водопритока в горизонтальных скважинах на месторождениях с трудноизвлекаемыми запасами нефти / Р.P. Кадыров, Р.Х. Низаев, А.Ф. Яртиев, В.В. Мухаметшин // Нефтяное хозяйство. - 2017. - № 5. - С. 44-47.

25. Мухалетшин В.В. Адаптация соляно-кислотного воздействия на залежах в карбонатных коллекторах // Нефтегазовое дело. - 2006. - Т. 4, № 1. - С. 127-131.

26. Снижение рисков принятия низкоэффективных управляющих решений при использовании кислотных составов, предотвращающих эмульсиообразование / В.В. Мухаметшин, В.Е. Андреев, Ю.В. Зейгман, Ю.А. Котенев, Ш.Х. Султанов // Геология, геофизика и разработка нефтяных и газовых месторождений. -2017 . - № 5. - С. 36-42.

27. Мухалетшин В.Ш. Промысловое обоснование выбора скважин и параметров воздействия при проведении солянокислотных обработок / В.Ш. Мухаметшин, А.М. Попов, А.М. Гончаров // Нефтяное хозяйство. - 1991. - № 6. - С. 32-33.

28. Каналин В.Г. Интерпретация геолого-промысловой информации при разработке нефтяных месторождений. - М.: Недра, 1984. - 184 с.

29. Добрынин B.M. Деформация и изменение физических свойств коллекторов нефти и газа. - М.: Недра, 1970. - 239 с.

30. Обоснование предельно-допустимых и оптимальных забойных давлений для карбонатных пластов (на примере турнейского яруса Красногорского месторождения) / К.М. Мусин, В.М. Хусаинов, Р.Р. Галлямов, Н.Х. Му- 
сабирова, А.А. Гибадуллин, К.Ф. Шипилова // Сборник научных трудов ТатНИПИнефть. - Москва: ЗАО «Издательство «Нефтяное хозяйство», 2015. Вып. 83. - С. 106-113.

31. Ахлетов Р.T. Интерпретация кривых капиллярного давления при смешанной смачиваемости / Р.Т. Ахметов, В.В. Мухаметшин, А.В. Андреев // Геология, геофизика и разработка нефтяных и газовых месторождений. - 2017. - № 4. C. 40-43.

32. Каналин В.Г. Исследование изменения коэффициента продуктивности при разработке залежей нефти Западной Сибири / В.Г. Каналин, М.К. Капралова // Нефтепромысловое дело. - 1981. - № 11. - С. 10-12.

33. Andreev A.V. Deposit Productivity Forecast in Carbonate Reservoirs with Hard to Recover Reserves / A.V. Andreev, V.Sh. Mukhametshin, Yu.A. Kotenev / SOCAR Proceedings, 2016. № 3. P. 40-45. DOI: dx.doi.org/10.5510/OGP20160300287.

34. Ахлетов P.T., Андреев А.В., Мухалетшин В.В. Методика прогноза остаточной нефтенасыщенности и коэффициента вытеснения по данным геофизических исследований для оценки эффективности применения нанотехнологий // Нанотехнологии в строительстве. - 2017. - Том 9, № 5. - С. 116-133. - DOI: dx.doi.org/10.15828/2075-8545-2017-9-5-116-133.

35. Прогноз показателя смачиваемости продуктивных пластов по объемному содержанию остаточной воды / Р.Т. Ахметов, Ю.В. Зейгман, В.В. Мухаметшин, А.В. Андреев, Ш.Х. Султанов // Известия ВУЗов. Нефть и газ. - 2017. - № 2. C. 39-43.

\section{УВАЖАЕМЫЕ КОЛЛЕГИ!}

ПРИ ИСПОЛЬЗОВАНИИ МАТЕРИАЛА ДАННОЙ СТАТЬИ

ПРОСИМ ДЕЛАТЬ БИБЛИОГРАФИЧЕСКУЮ ССЫЛКУ НА НЁ̈:

Мухалетшин В.В. Оценка эффективности использования нанотехнологий после завершения строительства скважин, направленных на ускорение ввода месторождений нефти в разработку // Нанотехнологии в строительстве. - 2018. - Том 10, № 1. C. 113-131. - DOI: dx.doi.org/10.15828/2075-8545-2018-10-1-113-131.

\section{DeAR COLleagues!}

THE REFERENCE TO THIS PAPER HAS THE FOLLOWING CITATION FORMAT:

Mukhametshin V.V. Efficiency estimation of nanotechnologies applied in constructed wells to accelerate field development. Nanotehnologii v stroitel'stve $=$ Nanotechnologies in Construction. 2018, Vol. 10, no.1, pp. 113-131. DOI: dx.doi.org/10.15828/20758545-2018-10-1-113-131. (In Russian). 